\title{
Benchtop hemodynamic studies of transcatheter valves: Has the horse come after the cart?
}

\author{
William M. DeCampli, MD, PhD
}

\author{
From The Heart Center at Arnold Palmer Hospital for Children, Orlando, Fla. \\ Disclosures: Author has nothing to disclose with regard to commercial support. \\ Received for publication Jan 8, 2016; accepted for publication Jan 8, 2016; available ahead of print Feb 10, 2016. \\ Address for reprints: William M. DeCampli, MD, PhD, Pediatric Cardiovascular Surgery, Arnold Palmer Hospital \\ for Children, 92 West Miller St, Orlando, FL 32806 (E-mail: William.decampli@orlandohealth.com). \\ J Thorac Cardiovasc Surg 2016;151:1060-1 \\ $0022-5223 / \$ 36.00$ \\ Copyright (c) 2016 by The American Association for Thoracic Surgery \\ http://dx.doi.org/10.1016/j.jtcvs.2016.01.011
}

In this issue of the Journal, Evin and colleagues ${ }^{1}$ report an in vitro study of the hemodynamic performance of the transcatheter SAPIEN valve (Edwards Lifesciences, Irvine, Calif) used as a mitral valve re-replacement (Figure 1). ${ }^{1}$ On the benchtop, the authors deployed the SAPIEN valve (sizes 23 and 26) into 3 different freshoff-the-shelf bioprostheses of several sizes (range, 23-31; total of 15 configurations). They used a standard benchtop circulatory system and pulse duplicator to create 8 representative hemodynamic configurations, and then they measured the effective orifice area, mean transvalvular gradient, and regurgitant fraction of each valve configuration. Among the 120 distinct simulations, they found generally acceptable flow characteristics. However, moderate or severe grade of valvar stenosis was associated with primary prosthesis measured internal orifice diameter less than $22 \mathrm{~mm}$, especially when the percentage oversizing of the SAPIEN valve was greater than $20 \%$.

The authors are to be applauded for acquiring the data on the hemodynamic behavior of this set of "valve-invalve" configurations using standardized measurement techniques. The results provide the clinician with provisional guidelines as to how to select an appropriate SAPIEN device size for a given prosthesis brand and size. On the other hand, the clinical experience implanting transcatheter valves into mitral prostheses began at least 7 years ago. A total of 68 cases have been reported in 9 clinical series and 20 to 30 cases reported in isolated case reports and abstracts. ${ }^{2,3}$ At least 6 distinct implantation systems have been used. In the Edwards series, the SAPIEN valve (the one used in the present study) largely has been supplanted by the SAPIEN XT, SAPIEN 3, and soon the self-expandable CENTERA valve. The clinical experience has shown that device type, size, and positioning must be determined by a set of patient-specific measurements since, for example, prosthetic "effective" internal orifice diameter is affected by the (variable) degree of leaflet thickening, calcification, and ring pannus formation on the bioprosthesis. In addition, device selection must be chosen to minimize

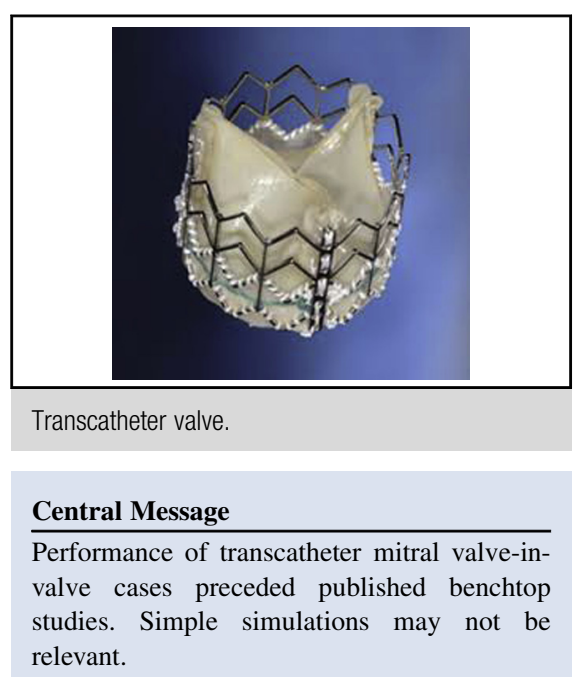

See Article page 1051 .

See Editorial page 906.

complications, such as migration, paravalvular leak, thrombosis, and left ventricular (LV) outflow track obstruction, which are also patient-specific. Algorithms for minimizing this set of complications still are to be determined. The cart has come before the horse, in the sense that in the development of transcatheter valve mitral therapy, we are now well beyond simplified benchtop models that use "fresh-off-the-shelf" bioprostheses positioned outside the spatial environment of the real LV inlet. Although continued preclinical investigations ideally may be preferred, the models will have to be very sophisticated incorporating, for example, patient-specific 3-dimensional printed models of the LV and "synthetically deteriorated" prostheses implanted within them. Equally, if not more likely, we will continue to learn from continued clinical experience how to optimally implant a transcatheter valve to achieve minimal transvalvular gradient and avoid the early complications described. In fact, clinical trials specifically focusing on developing implantation algorithms should be carried out, rather than relying on a retrospective meta-analysis of a myriad of small published series. Perhaps the number of distinct deployment systems (brands) should be limited, so the task is accomplished in a reasonable time period. To determine the longer-term effectiveness of the procedure (compared with transcatheter mitral repair or 


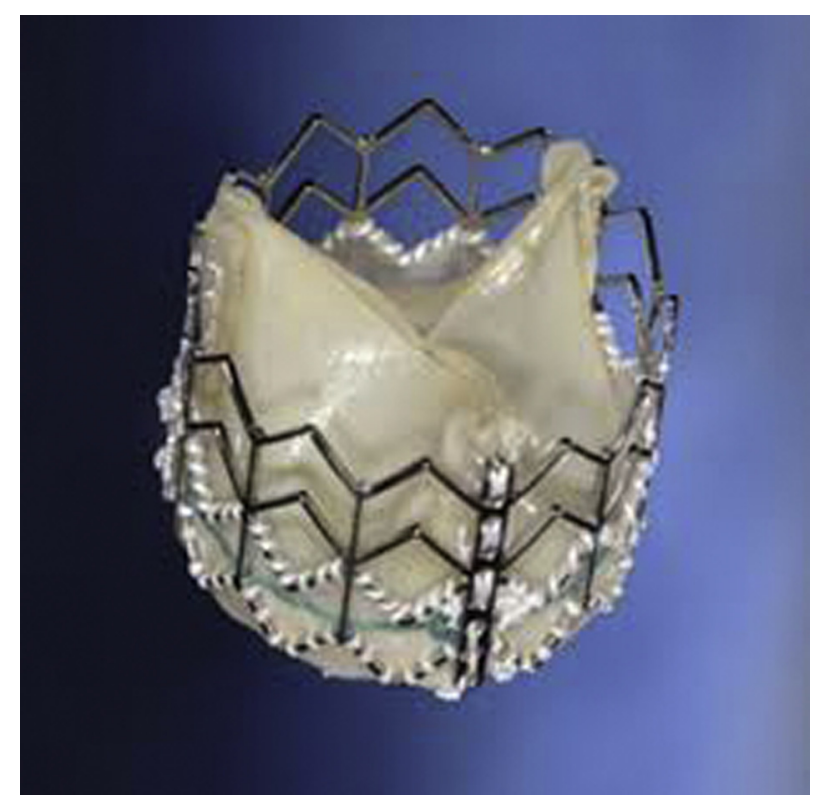

FIGURE 1. SAPIEN transcatheter valve (Edwards Lifesciences, Irvine, Calif) tested for use within failed mitral prosthesis.

surgical re-replacement), clinical trials similar to the Placement of Aortic Transcatheter Valves (PARTNER) series or Endovascular Valve Edge-to-Edge Repair Study
(EVEREST II) will be needed. The Mitral Valve Academic Research Consortium has just published recommendations for clinical trial design principles and end point definitions for transcatheter replacement of the native mitral valve. ${ }^{4}$ Recommendations specifically targeting trial designs for the valve-in-prosthesis procedure have not been formulated, but the Mitral Valve Academic Research Consortium recommendations will be a good starting template. In fact, transcatheter valve-in-prosthesis recommendations may be more straightforward to formulate than the transcatheter valve-in-native mitral recommendations.

\section{References}

1. Evin M, Guivier-Curien C, Rieu R, Rodes-Cabau J, Pibarot P. Mitral valve-invalve hemodynamic performance: an in-vitro study. J Thorac Cardiovasc Surg. 2016;151:1051-9.e6.

2. Praz F, Windecker S, Huber C, Carrel T, Wenaweser P. Expanding indications of transcatheter heart valve interventions. JACC Cardiovasc Interv. 2015;8: 1777-96.

3. Bouleti C, Fassa AA, Himbert D, Brochet E, Ducrocq G, Nejjari M, et al Transfemoral implantation of transcatheter heart valves after deterioration of mitral bioprosthesis or previous ring annuloplasty. JACC Cardiovasc Interv. 2015;8:83-91

4. Stone GW, Adams D, Abraham W, Kapppetein A, Généreux P, Vranckx P, et al Clinical trial design principles and endpoint definitions for transcatheter mitral valve repair and replacement: Part 2: Endpoint definitions: a consensus document from the mitral valve academic research consortium. J Am Coll Cardiol. 2015;66: $308-21$. 